Research Article

\title{
The Interaction Force between Scheelite and Scheelite/Fluorite/ Calcite Measured Using Atomic Force Microscopy
}

\author{
Junyan Yang $\mathbb{D}^{1,2,3,4}$ Shen $Q i \mathbb{D}^{1,3,4}$ Bo Song $\mathbb{D}^{2}{ }^{2}$ Qi Zheng $\mathbb{D}^{1,3,4}$ Xiaokui Che $\mathbb{D}^{1,3,4}$ \\ and Lijun Wang $\mathbb{D}^{1,3,4}$ \\ ${ }^{1}$ National Engineering Laboratory of Biohydrometallurgy, GRINM Group Corp., Ltd., Beijing 100088, China \\ ${ }^{2}$ School of Metallurgical and Ecological Engineering, University of Science and Technology Beijing, 100083 Beijing, China \\ ${ }^{3}$ GRINM Resources and Environment Tech. Co., Ltd., 100088 Beijing, China \\ ${ }^{4}$ General Research Institute for Nonferrous Metal, Beijing 100088, China
}

Correspondence should be addressed to Junyan Yang; yang8865139@163.com and Lijun Wang; gold@grinm.com

Received 5 November 2019; Revised 4 January 2020; Accepted 10 January 2020; Published 11 February 2020

Guest Editor: Yaowen Xing

Copyright (C) 2020 Junyan Yang et al. This is an open access article distributed under the Creative Commons Attribution License, which permits unrestricted use, distribution, and reproduction in any medium, provided the original work is properly cited.

\begin{abstract}
The mechanism of the formation of the hydrophobic agglomerate in fine scheelite flotation was studied using zeta potential measurement, contact angle measurement, optical microscope measurement, and atomic force microscopy (AFM) colloid probe technology. Zeta potential measurement results confirmed the adsorption of sodium oleate on scheelite, fluorite, and calcite surface and surface potential difference at different $\mathrm{pH}$ values of ultrapure water. Contact angle measurement results confirmed the surface of nature scheelite, fluorite, and calcite was hydrophilic, and the surface after thread by sodium oleate solution was hydrophobic. The optical microscope measurement results confirmed the agglomerates could really form in ultrapure water of $\mathrm{pH}$ 8 or 10 and in $1 \mathrm{mM}$ sodium oleate solution of $\mathrm{pH} 10$. The agglomerations were empty and not tight in ultrapure water. On the contrary, the hydrophobic agglomerations were larger and denser after treated with sodium oleate solution than that of in ultrapure water. According to the AFM experiment results, the interaction forces on hydrophilic scheelite-scheelite and scheelitefluorite were repulsive at $\mathrm{pH} 5.6$ and attractive at $\mathrm{pH} 8$ or 10. However, the interaction forces on hydrophilic scheelite-calcite were attractive at $\mathrm{pH} 5.6,8$ or 10. The interaction forces on hydrophobic scheelite-scheelite, scheelite-fluorite, and scheelite-calcite were attractive strongly due to the existence of hydrophobic force. The measurement results of the interaction forces were in good agreement with the changes of zeta potential and contact angle at different conditions. The combined results could be beneficial to understand the interaction force in fine scheelite flotation.
\end{abstract}

\section{Introduction}

Froth flotation has been considered as one of the most widely used methods for the separation of minerals [1]. It is the most efficient when the mineral particle sizes are between $10 \mu \mathrm{m}$ and $100 \mu \mathrm{m}$. However, the flotation of fine mineral particles of less than $10 \mu \mathrm{m}$ is still a technical challenge [2-4]. Scheelite is a kind of easily slimed mineral. In the grinding process of scheelite, a large number of fine slimes can be produced, which seriously affects the flotation efficiency of scheelite [1]; this is because many calcium-bearing minerals (fluorite and calcite) exhibit similar surface properties to scheelite. In order to solve this problem, many works including shear flocculation flotation [5], carrier flotation [6], selective flocculation flotation [7], and density functional theory calculation [8] had been researched by a large number of researchers, which had achieved remarkable achievements. Flotation agents can improve effectively the separation effect of calcium-bearing minerals in flotation processing. The $\mathrm{Pb}-\mathrm{BHA}$ complexes were used in flotation separate scheelite from fluorite and calcite $[9,10]$, increasing the recovery of scheelite. The rheological control of the flotation pulp by using garnet makes a significant improvement in fine scheelite flotation [11]. There exists strong correlation among the flotation rate, pulp rheology, froth, and floc morphology in the cleaning flotation, so the 
formation of aggregates is very important for fine scheelite flotation.

The formation mechanism of hydrophobic agglomerates had been widely studied. The hydrophobic association between collector molecules and mineral surface and the hydrophobic interaction energy between mineral particles were the reasons for the formation of hydrophobic agglomerates $[5,12]$, and the capillary condensation of collector and the bridge chain were conducive to the formation of agglomerations [13]. The DLVO and EDLVO theory were also used to describe the agglomeration and dispersion of fine particles in solution. The phenomenon of adsorption, collision, and adhesion on the mineral's surface after adding collector could not be described very well by DLVO theory [14], but the EDLVO theory explained that hydrophobic force [15] was the original cause of agglomeration of mineral particles [16].

The formation mechanism of hydrophobic agglomerates was explained from the aspects of adsorption, colloidal interface, and theoretical calculation. However, the mechanism was still unclear at the micro-nano scale because of the complexity of experimental verification. Surface and interface forces (van der Waals force, electrical double layer force, hydration force, hydrophobic force, etc.) are significant for understanding the interaction between particles in the flotation system $[17,18]$. Atomic force microscopy (AFM), as a surface and interface force measuring technology $[19,20]$, is used widely at the micro-nano scale. The hydrophilic/hydrophobic force had been studied by researchers since the AFM was developed [21-23], especially with the colloid probe technology [24, 25]. Ducker et al. [26] directly measured the colloidal force between silica microspheres and substrate in sodium chloride solution using AFM firstly; meanwhile, Butt [27] measured the colloidal force in different concentrations of potassium chloride and magnesium chloride electrolyte solutions with colloidal probes. All the microspheres used in the above studies were surface smooth, spherical particles of defined radius, which is conducive to the direct measurement and quantitative analysis of force curves [19]. However, the actual shape of mineral particles cannot be spherical and the surface is rough, so it is difficult to analyse quantitatively the interaction force between actual particle and surface. Gui et al. [25] studied the interaction between coal and coal, kaolinite and kaolinite, and coal and kaolinite in deionized aqueous solution by colloidal probe technology. The repulsion between kaolinite and kaolinite made it difficult for fine kaolinite to sedimentation at natural $\mathrm{pH}$, which was harmful in coal flotation. The interaction between fluorite particles and scheelite surface was measured at the condition of different $\mathrm{pH}$ values and various concentration of calcium ion [28]. The adhesion between fluorite and scheelite surface was enhanced remarkably after adding calcium ion, while the adhesion between fluorite and scheelite surface was reduced significantly by using sodium silicate as inhibitor.

In this study, the interaction forces between scheelite particle and scheelite surface, scheelite particle and fluorite surface, and scheelite particle and calcite surface in ultrapure aqueous solution and sodium oleate solution system were studied by using the AFM colloidal probe technique. However, it must be pointed out that the irregularity of the scheelite particles and the nano-heterogeneity [29] of the mineral surface make it difficult to measure the surface force quantitatively. The force curve obtained in the experiment is also difficult to fit quantitatively with DLVO theory and EDLVO theory, but it can still be described qualitatively [25]. The experimental results contribute to understanding the formation mechanism of agglomerations in the flotation process of fine scheelite and provide guidance for the separation of scheelite from calcite and fluorite.

\section{Materials and Methods}

2.1. Minerals and Reagents. Pure minerals of scheelite, fluorite, and calcite were bought from Taobao; the three minerals samples were crushed by a hand hammer, and several pieces were cut to obtain cuboid of $1 \mathrm{~cm}$ length, $0.8 \mathrm{~cm}$ width, and $0.5 \mathrm{~cm}$ high for contact angle and AFM measurements. The rest of the scheelite sample was further purified using an optical microscope and then was milled into $38-75 \mu \mathrm{m}$ powder particle using an agate mortar. Chemical analysis showed that the purity of calcite, fluorite, and calcite was $94.56 \%, 98.17 \%$, and $98.29 \%$, respectively. X-ray diffraction (XRD) analysis of the scheelite power revealed that the mineral was pure scheelite (Figure 1). The collector sodium oleate (analytical grade, Sinopharm Chemical Reagent Co., Ltd) was used for soaking three minerals. $\mathrm{NaOH}$ (analytical grade, Sinopharm Chemical Reagent Co., Ltd) was used to adjust the $\mathrm{pH}$ of the solutions; ultrapure water was used in the all experiments (resistivity of $18.2 \mathrm{M} \Omega \cdot \mathrm{cm}$; conductivity of $0.054 \mu \mathrm{s})$.

2.2. Zeta Potential Measurements. Zeta potential measurements were carried out on dilute dispersions of three minerals of particle size less than $5 \mu \mathrm{m}$ using a Malvern Zeta sizer ZS90. Steps are as follows: weigh three minerals $0.005 \mathrm{~g}$ into a beaker and then add $50 \mathrm{ml}$ of ultrapure water/ $1 \mathrm{mM}$ sodium oleate solution. Suspensions of the minerals were dispersed by magnetic stirring for $10 \mathrm{~min}$ at room temperature; after $30 \mathrm{~min}$, the specific $\mathrm{pH}$ value was then adjusted by $\mathrm{HCl}$ or $\mathrm{NaOH}$ solution; the $\mathrm{pH}$ was measured and liquid supernatant was used for zeta potential measurement. Repeat determination at least three times for each sample.

2.3. Preparation of Surface. The sample is usually a basal plane with a planar, nano-level smooth surface in the AFM experiment [30]. Surface of natural minerals are generally rough, so scheelite, fluorite, and calcite were lapped using 800 mesh, 1200 mesh, 1500 mesh sandpaper in turn, polished with aluminium oxide powder $(0.02 \mu \mathrm{m})$ using a metallographic polishing machine (MP-1), and then washed with ultrapure water five times and dried with high-pure $\mathrm{N}_{2}$ (Figure 2). The Scanasyst-air probe (elastic coefficient $0.4 \mathrm{~N} /$ $\mathrm{m})$ was used for roughness measurement of the three mineral substrates by atomic force microscopy (Dimension FastScan Bruker, Germany). The roughness of scheelite, fluorite, and calcite substrates was $11.9 \mathrm{~nm}, 14.3 \mathrm{~nm}$, and 


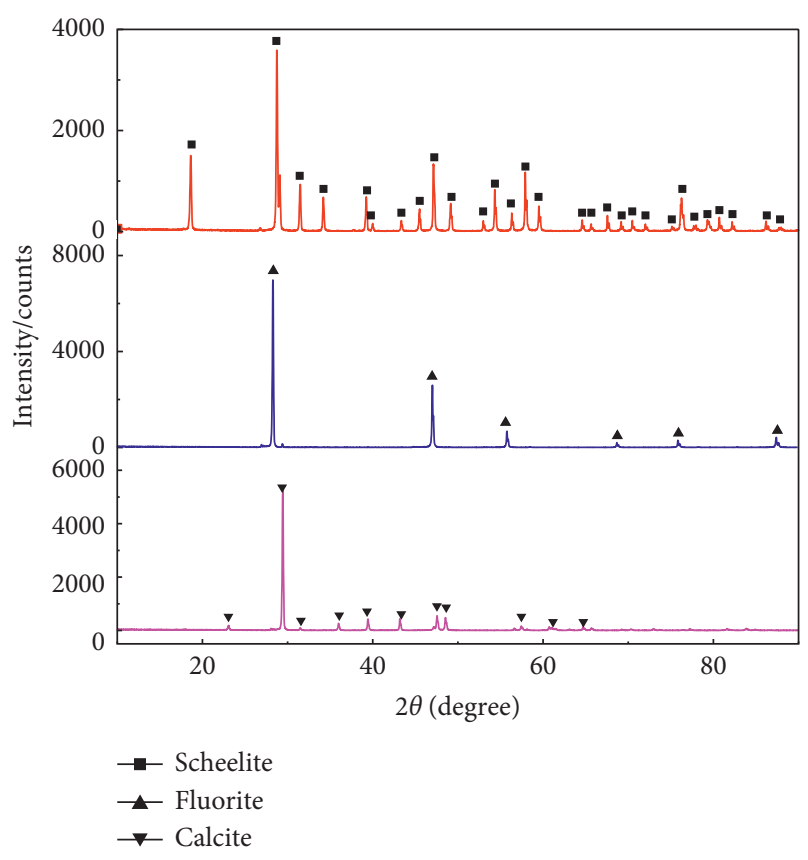

FIGURE 1: XRD patterns of powder scheelite, fluorite, and calcite for the AFM experiments and zeta potential measurements.

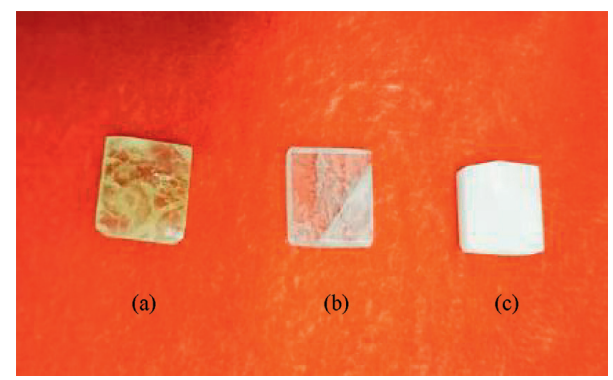

Figure 2: The surface of minerals: (a) scheelite, (b) fluorite, and (c) calcite.

$12.3 \mathrm{~nm}$ in turn. The three mineral substrates were soaked in ultrapure water $(\mathrm{pH}=5.6,8,10)$ and $0.1 \mathrm{mM} / 1 \mathrm{mM}$ sodium oleate solution of $\mathrm{pH} 10$ for 30 minutes, which were used for AFM experiments and contact angle measurements.

2.4. Contact Angle Measurements. The sessile drop method was carried out using a dynamic contact angle meter (DSA 100 , Krüss $\mathrm{GmbH}$, Germany) between ultrapure water drop (pH 5.6) and mineral substrates. Three mineral substrates prepared in section 2.3 were used for contact angle measurements. The average angle of three different area measurements was recorded as the final contact angle. This method is consistent with the literature [31].

2.5. Optical Microscope Measurements. Scheelite-scheelite, scheelite-fluorite, and scheelite-calcite powders $(1 \mathrm{~g})$ were put into a beaker and then $50 \mathrm{ml}$ of ultrapure water was added. After 10 minutes of stirring using a magnetic stirrer, a drop was sucked onto the slide and a metallographic microscope (9XB-PC, Shanghai China) was used to see if the agglomerates had formed.

2.6. AFM Experiments and Tip Modification. Surface force measurements on scheelite particle and three mineral substrates (scheelite, fluorite, and calcite) were carried out in aqueous solutions at various $\mathrm{pH}$ values $(5.6,8$, and 10$)$ using a Multimode 8 AFM instrument (Bruker, Germany) in contact mode. The N-type silicon AFM probe (CSC37/ Tipless/No Al, MikroMasch, Estonia) was used to prepare the scheelite colloid probe for interaction force measurements. Scheelite powders of $38-75 \mu \mathrm{m}$ were selected evenly dispersed on the silicon chip, and then the sphere particle was selected under the light microscope; after that, the epoxy resin $A B$ blue was coated around the target particle. The probe was moved over the target particle, put down slowly until contacting with epoxy resin $\mathrm{AB}$ glue, and lifted quickly. Then the target particle was glued by the tip of probe within $10 \mathrm{~min}$. The scheelite colloid probe is shown in Figure 3. In the schematic diagram of AFM (Figure 4), the sample was scanned by a scheelite colloid probe, which was mounted to a cantilever spring. The forces between the scheelite colloid probe and the samples were measured by monitoring the deflection of the cantilever. The cantilever will swing after the tip touches the sample, the laser shines on the end of the cantilever, and the position of the reflected light will also change, which will cause the offset. The photodetector records offset and converts them into electrical signals, which were converted to force-versus-distance curves. Before the force curve measurement, the mineral substrate was put into the sample chamber. One or two drops of ultrapure water were dropped on the substrate, and the scheelite colloidal probe was moved into the water drop. The cantilever elastic coefficient was corrected by the Sader method, and the elastic coefficient was $0.3060-0.3794 \mathrm{~N} / \mathrm{m}$. After the setpoint, ramp size $(1 \mu \mathrm{m})$, and ramp rate $(0.01 \mathrm{~Hz})$ were set, the force curve measurements was started, and four different points were selected for each condition. The force curve was analysed using the offline software NanoScope analysis 1.8.

AFM force-displacement curves are shown in Figure 5. At position 1, the tip is far away from the sample, and there is no interaction force between the tip and the sample. As the tip moves downward, the tip is attracted to the surface of the sample at position 2; this phenomenon is called "jump-in" in the experiment. As tip continued down, the cantilever begins to change deformation, and then the tip began to press the surface of the sample, as shown at position 3 , and the force was repulsive. When the deformation of the cantilever reaches the set limit, the tip starts to go up at position 4 . Due to the adhesive effect of the sample on the tip, the tip will not rise synchronously with the rise of the cantilever. Until the detachment force generated by the bending deformation of the cantilever and the adhesion force reach equilibrium, the tip will be separated from the sample at position 5. This phenomenon is called "jump-out" in the experiment. There is no interaction force between tip and surface along with the separation distance increases. 


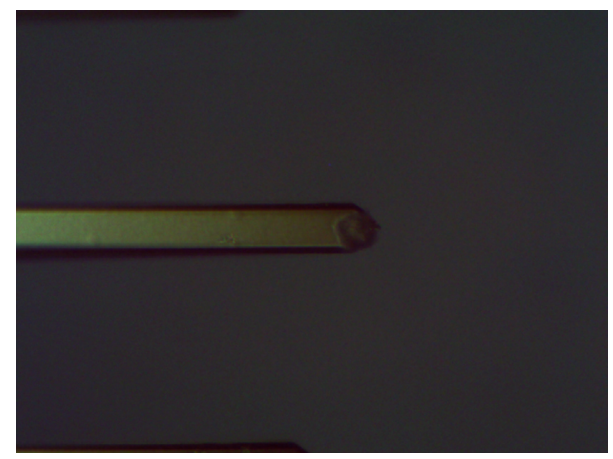

FIGURE 3: The photo of scheelite particle probe.

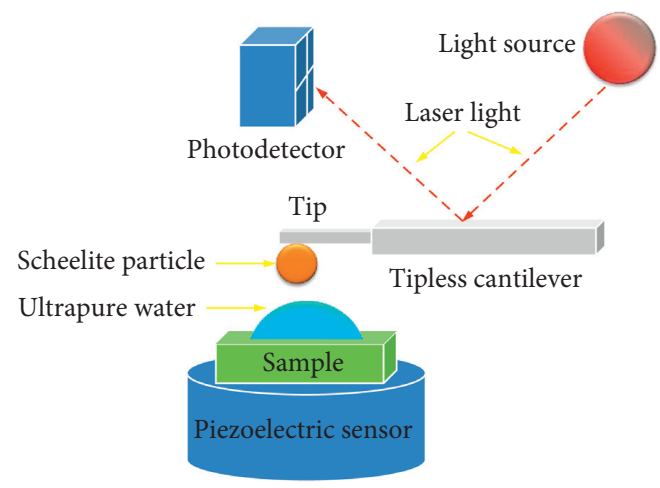

Figure 4: Schematic diagram of AFM.

\section{Results and Discussion}

3.1. Zeta Potential Measurements. Figure 6 shows the zeta potentials of scheelite, fluorite, and calcite at different $\mathrm{pH}$ values in aqueous solutions (Figure 6(a)) and $1 \mathrm{mM}$ sodium oleate solution (Figure 6(b)). The zeta potentials of scheelite were negatively charged from $\mathrm{pH} 2$ to $\mathrm{pH} 12$ and $-30.87 \mathrm{mv}$ at $\mathrm{pH}$ 9. An isoelectric point (IEP) of scheelite was not observed, which was consistent with the literature [32]. The isoelectric point (IEP) of fluorite and calcite, respectively, was about at $\mathrm{pH} 8.4 \pm 0.1$ and $\mathrm{pH} 9.4 \pm 0.1$, which was also consistent with the previous reports [33]. When the three minerals were treated with $1 \mathrm{mM}$ sodium oleate solution, the zeta potentials become more negative at various $\mathrm{pH}$ values; it is probably due to the adsorption of the sodium oleate on the surface of minerals $[34,35]$. To contrast the adsorption effect of three minerals surface, contract angles were measured in the next section.

3.2. Contact Angle Measurements. As shown in Figure 7, natural minerals of scheelite, fluorite, and calcite had strong hydrophilicity [36]; contact angles were, respectively, scheelite-27.30 (Figure 7(a)), fluorite-36.90 (Figure $7(\mathrm{c})$ ), and calcite- $38.80^{\circ}$ (Figure $7(\mathrm{e})$ ), so the natural floatability of the three minerals were calcite $>$ fluorite $>$ scheelite. Contact angles suddenly increased significantly to scheelite-93.60 (Figure $7(\mathrm{~b})$ ), fluorite-91.00 (Figure $7(\mathrm{~d})$ ), and calcite-80.90 (Figure $7(\mathrm{f})$ ). Therefore, the hydrophobicity of three minerals obviously increased, and scheelite had best floatability than other minerals. The adsorption of sodium oleate on the mineral surface was also confirmed, which was in agreement with zeta potential measurement results .

3.3. Optical Microscope Measurements. As shown in Figures 8-10, scheelite and scheelite, scheelite and fluorite, and scheelite and calcite particles could attract each other to form agglomeration in the ultrapure water solution of $\mathrm{pH} 8$ and 10, but the agglomerations were empty and not tight. As shown in Figure 11, the agglomerations were larger and denser when the particles of scheelite, fluorite, and calcite were soaked by sodium oleate.

\subsection{AFM Experiments.}

Derjaguin-Landau-Verwey-Overbeek (DLVO) theory $[37,38]$ was used to predict the dispersion and aggregation of colloidal particles in colloidal chemistry. DLVO forces are composed of van der Waals force $\left(F_{\mathrm{vdm}}\right)$ and double electrical layer force $\left(F_{\text {edl }}\right)$, and the total interaction forces are the sum of two forces. Therefore, the total interaction forces are given by equation (1). According to the DLVO theory, the stability of the dispersion system depends on the relative relationship between the van der Waals force and the electrical double layer force. The van der Waals attraction force occupies the dominant role when the separation distance is long. As the separation distance decreases, the repulsive force of the electrical double layer increases gradually to prevent the particles from attracting each other. In the flotation process, the hydrophobic force overcomes the repulsion of the electrical double layer after the collector is added. Usually, when the distance between particles is less than $20 \mathrm{~nm}$ [39], the hydrophobic particles attract each other and form agglomerates.

$$
F_{t}=F_{\text {edl }}+F_{\mathrm{vdm}} .
$$

The electrical double layer structure is a common phenomenon in the solid-liquid interface. The mineral surface will be charged when the mineral surface contacted the solution, which may be originated from the dissolution of surface groups [18], the adsorption of ions, or the charge exchange mechanism. The opposite charge of ions is balanced by counterions to sustain the colloidal system electrically neutral. Therefore, the electric double layer structure is formed at the solid-liquid interface. The electrical doublelayer force exhibits a repulsive interaction on the condition of the unique surface charge. On the contrary, an attractive force is produced in situation of the opposite surface charge. The electrical double-layer force between a sphere with radius $R$ and a plane can be described by the following equations [18]:

$$
\begin{gathered}
F_{\text {edl }}=\gamma R Z e^{-k D}, \\
Z=64 \pi \varepsilon_{0} \varepsilon\left(\frac{k T}{e}\right)^{2} \tanh ^{2}\left(\frac{z e \Psi_{0}}{4 k T}\right)=\left(9.22 * 10^{-11}\right) \tanh ^{2}\left(\frac{\Psi_{0}}{103}\right),
\end{gathered}
$$




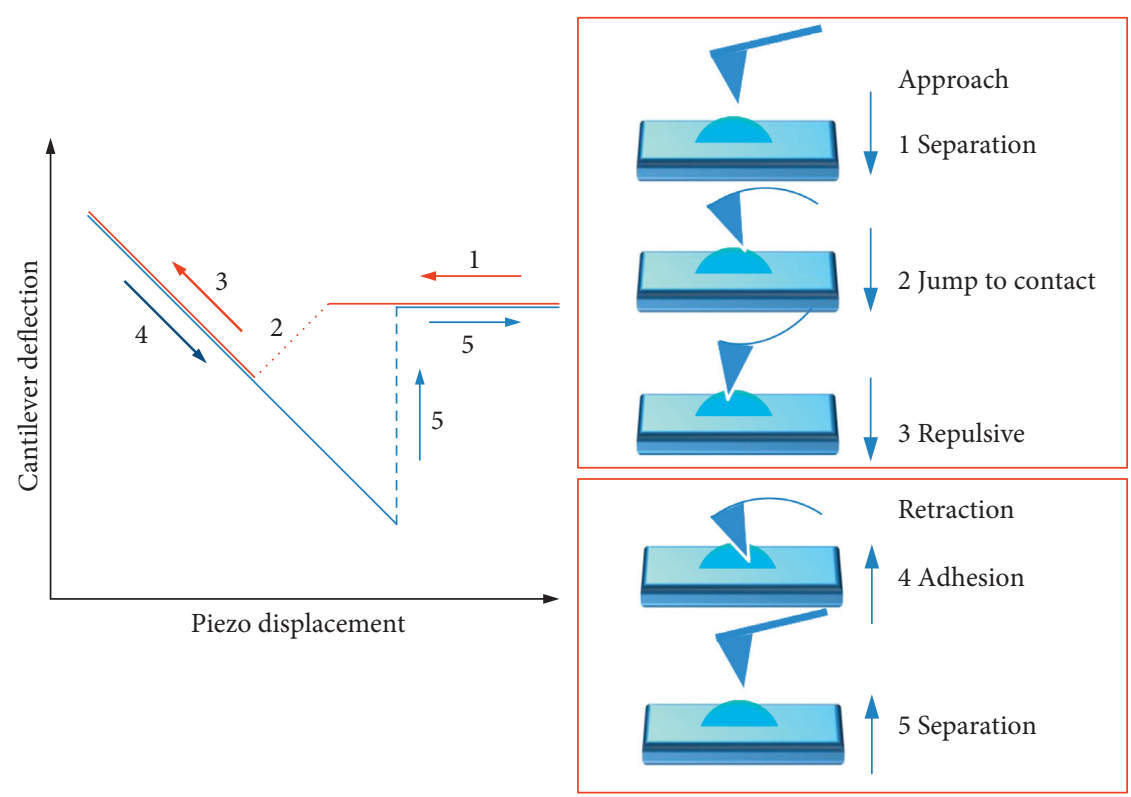

Figure 5: AFM force-displacement curves (left) and the related cantilever (right).

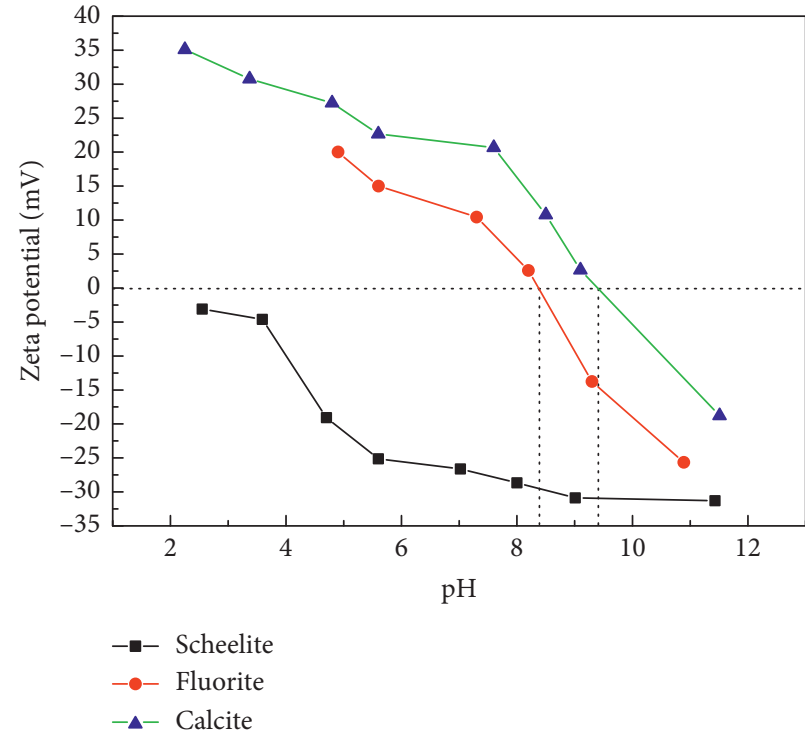

(a)

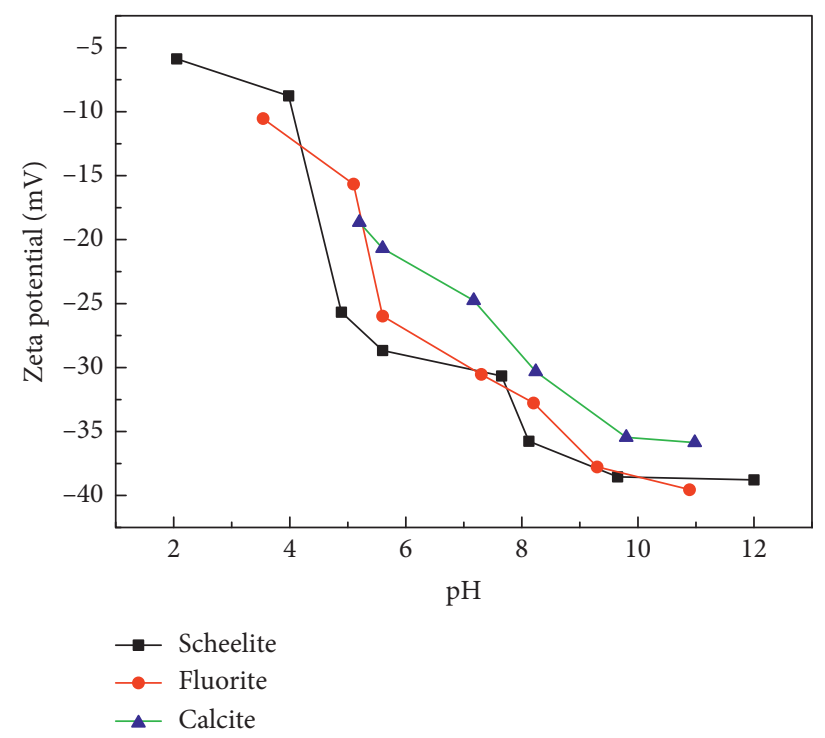

(b)

FIGURE 6: Zeta potentials of scheelite, fluorite, and calcite in (a) aqueous solution and (b) $1 \mathrm{mM}$ sodium oleate solution.

$$
\gamma^{-1}=\frac{0.304 * 10^{-9}}{\sqrt{M} m},
$$

where $\gamma^{-1}$ is the Debye length, $M$ is the electrolyte concentration, $R$ is the scheelite sphere radius, $Z$ is the interaction coefficient, $D$ is the separation distance between scheelite sphere and mineral flat substrate, $\varepsilon$ is the relative permittivity of the medium, $\varepsilon_{0}$ is the vacuum permittivity, $k$ is the Boltzmann constant, and $\Psi_{0}$ is the surface potential of minerals. van der Waals force is a common surface force, which consists of three forces: dispersion force, induction force, and orientation force. All of these three forces decay with the seventh power of the distance between molecules. At a larger distance $(H>10 \mathrm{~nm})$, due to the electromagnetic delay effect, the dispersion force decays 10 times faster. The resultant force of van der Waals interaction is dominated by dispersion force in aqueous solution. van der Waals force is calculated mainly by Hamaker approximation and/or Lifshitz approximation. It can be described by the following equation [18]: 


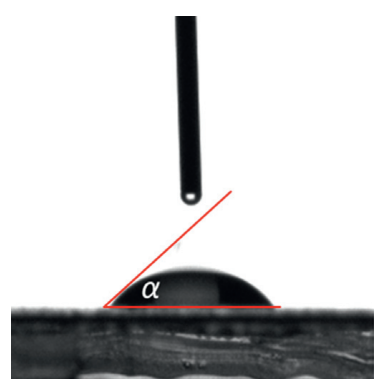

(a)

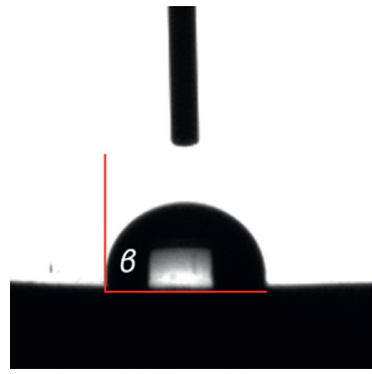

(d)

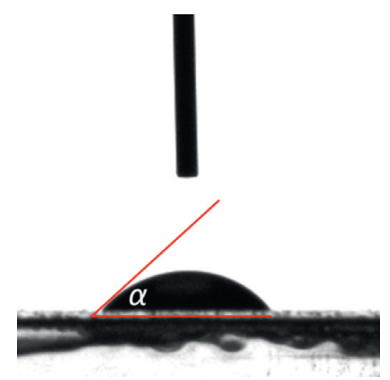

(b)

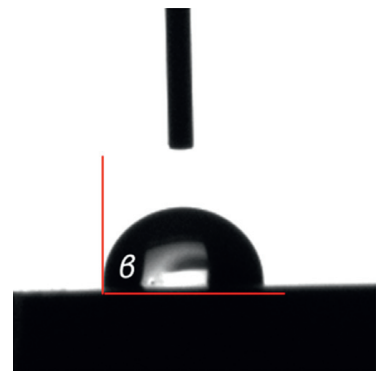

(e)

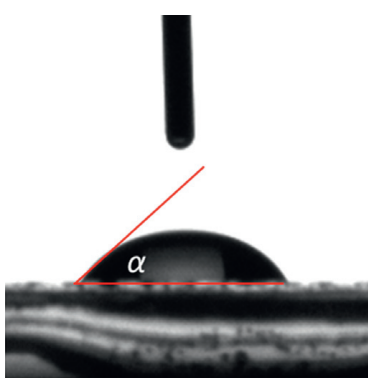

(c)

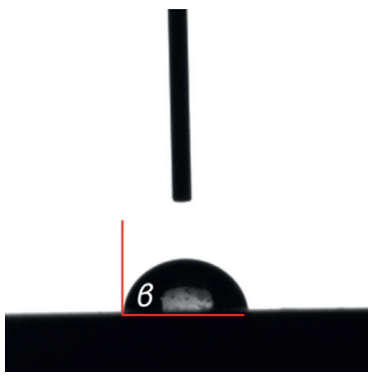

(f)

Figure 7: Contact angle of freshly exfoliated minerals substrates ((a) scheelite, (c) fluorite, and (e) calcite) and 1 mM sodium oleate solution soaked minerals substrates ((b) scheelite, (d) fluorite, and (e) calcite). (a) scheelite $27.30^{\circ}$ (b) scheelite $93.60^{\circ}$ (c) fluorite $36.90^{\circ}$ (d) fluorite $80.90^{\circ}$ (e) calcite $38.80^{\circ}$ (f) calcite $91.00^{\circ}$.

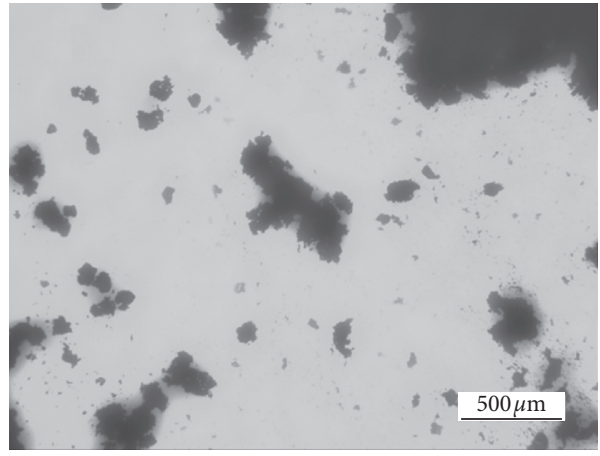

(a)

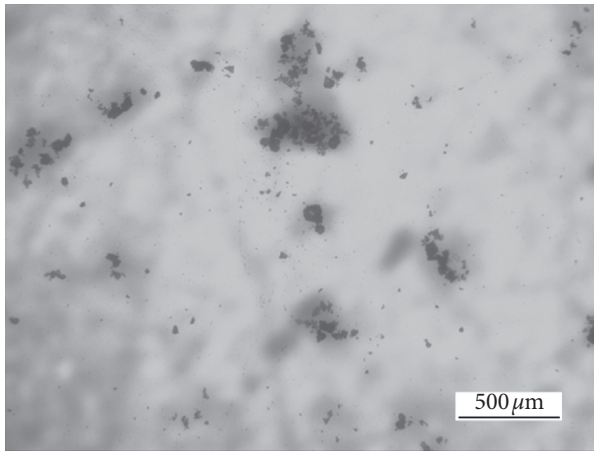

(b)

FIGURE 8: Scheelite particles $(-10 \mu \mathrm{m})$ in ultrapure water: (a) $\mathrm{pH} 8$; (b) $\mathrm{pH} 10$.

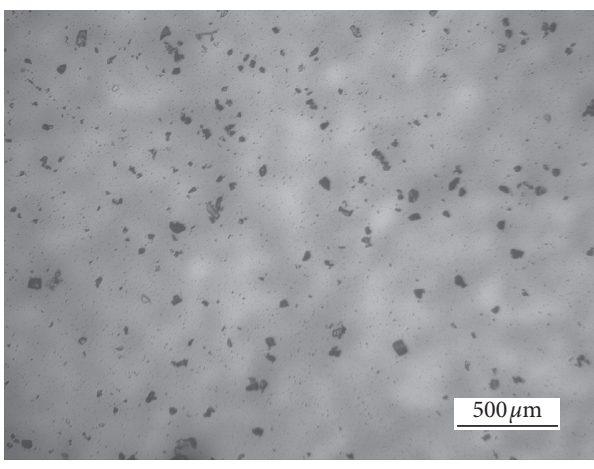

(a)

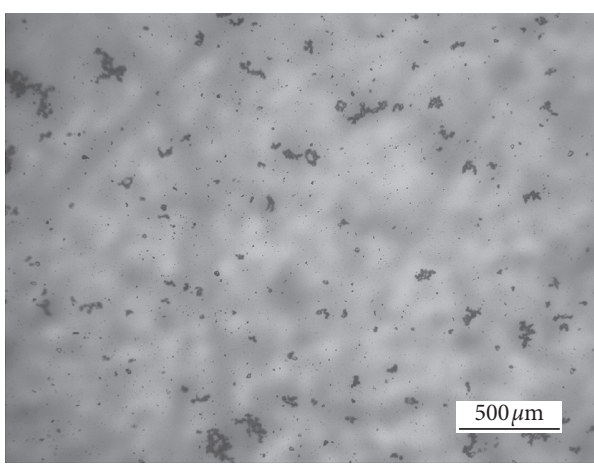

(b)

FIGURE 9: Scheelite and fluorite particles $(-10 \mu \mathrm{m})$ in ultrapure water: (a) $\mathrm{pH}$ 8; (b) $\mathrm{pH} 10$. 


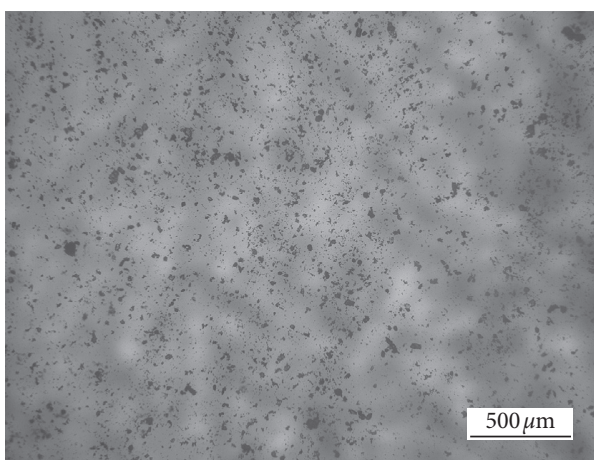

(a)

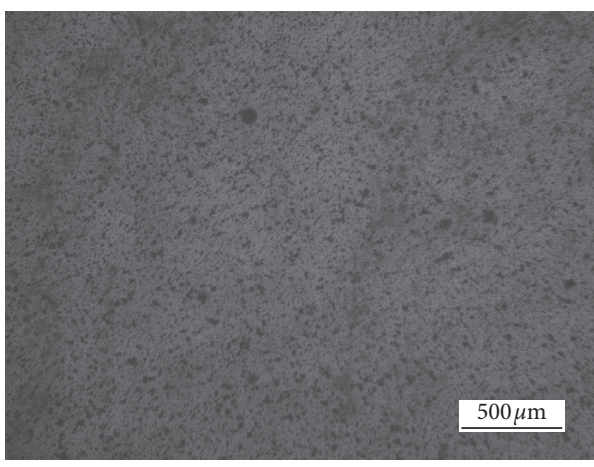

(b)

Figure 10: Scheelite and calcite particles $(-10 \mu \mathrm{m})$ in ultrapure water: (a) $\mathrm{pH}$ 8; (b) $\mathrm{pH} 10$.

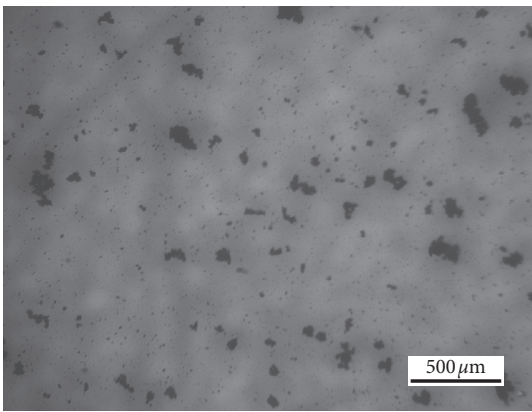

(a)

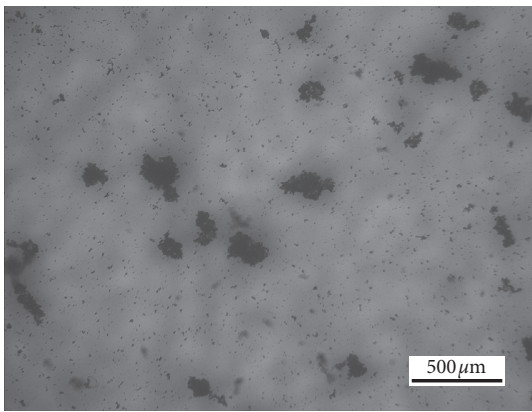

(b)

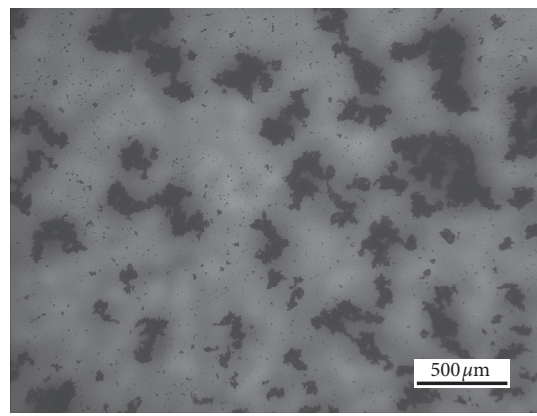

(c)

FIGURE 11: Particles $(-10 \mu \mathrm{m})$ in $1 \mathrm{mM}$ sodium oleate solution at $\mathrm{pH}$ 10: (a) scheelite-scheelite and scheelite-calcite; (b) scheelite-fluorite; (c) scheelite-calcite.

$$
\begin{aligned}
& F_{\mathrm{vdw}}=-\frac{A R}{6 D^{2}}, \\
& A_{132}=\left(\sqrt{A_{11}}-\sqrt{A_{33}}\right)\left(\sqrt{A_{22}}-\sqrt{A_{33}}\right),
\end{aligned}
$$

where $A$ is the Hamaker constant, $R$ is the scheelite sphere radius, $D$ is the separation distance between scheelite sphere and mineral flat substrate, $A_{132}$ is the Hamaker constant between mineral 1 and mineral 2 immersed in medium 3 , and $A_{11}, A_{22}$, and $A_{33}$ are the Hamaker constants for the interactions between two identical media containing minerals 1,2 , or 3 in vacuum. However, there were still nonDLVO forces at complex conditions, which could be described with the EDLVO theory. Hydration force $\left(F_{\text {hydration }}\right)$ and hydrophobic force $\left(F_{\text {hydrophobic }}\right)$ were two typical nonDLVO forces [17].

$$
\begin{aligned}
F_{t} & =F_{\text {edl }}+F_{\mathrm{vdm}}+F_{\text {Hydration }}, \\
F_{t} & =F_{\text {edl }}+F_{\text {vdm }}+F_{\text {hydrophobic }} \\
F_{\text {hydration }} & =2 \pi \frac{R_{1} R_{2}}{R_{1}+R_{2}} K_{\text {hydration }} \exp \left(\frac{-D}{\gamma^{-1}}\right), \\
F_{\text {hydrophobic }} & =K_{\text {hydrophobic }} \exp \left(\frac{-D}{\gamma^{-1}}\right),
\end{aligned}
$$

where $R_{1}$ and $R_{2}$ are the scheelite sphere radii, $\gamma-1$ is the Debye length, $K_{\text {hydration }}$ is the hydrophilic force constant, $K_{\text {hydrophobic }}$ is the hydrophobic force constant, and $D$ is the separation distance between scheelite sphere and mineral flat substrate.

According to equation (6), the Hamaker constant on scheelite-scheelite, scheelite-fluorite, and scheelite-calcite in pure water is calculated using the Hamaker constant of Table 1, and the results are $1.35 E-20,6.50 E-21$, and 1.77E-20. Similarly, the Hamaker constant between scheelite and scheelite, scheelite and fluorite, and scheelite and calcite immersed in sodium oleate is $9.89 E-21$, $3.89 E-21$, and $1.35 E-20$. According to equation (5), the van der Waals forces between scheelite and scheelite, scheelite and fluorite, and scheelite and calcite are all negative in pure water and sodium oleate solution. Combining equations (1)-(4), DLVO and EDLVO forces on scheelitescheelite, scheelite-fluorite, and scheelite-calcite were calculated. As shown in Figure 12, the DLVO and EDLVO forces on scheelite-scheelite, scheelite-fluorite, and scheelitecalcite were all negative in pure water of $\mathrm{pH} 8$ or 10 and $1 \mathrm{mM}$ sodium oleate solution of $\mathrm{pH} 10$, which means that agglomerates on scheelite-scheelite, scheelite-fluorite, and scheelite-calcite could be formed easily in pure water of $\mathrm{pH} 8$ or 10. The EDLVO forces were more negative because of the existence of hydrophilic force. This is consistent with the results of the optical microscope experiments. 
TABLe 1: Hamaker constant for two identical media in vacuum.

\begin{tabular}{lcc}
\hline Medium & Hamaker constant & References \\
\hline Pure water & $4.00 E-20$ & {$[15]$} \\
Sodium oleate & $4.70 E-20$ & {$[40]$} \\
Scheelite & $1.00 E-19$ & {$[41]$} \\
Fluorite & $6.55 E-20$ & {$[42]$} \\
Calcite & $1.24 E-19$ & {$[40]$} \\
\hline
\end{tabular}

3.4.1. Interaction Forces on Scheelite-Scheelite, ScheeliteFluorite, and Scheelite-Calcite in Ultrapure Water. The interaction forces were measured on scheelite-scheelite, scheelite-fluorite, and scheelite-calcite in ultrapure water. As shown in Figure 13(a). The measured forces as a function of separation distance showed repulsion during approach at natural $\mathrm{pH} 5.6$ between scheelite particle and scheelite substrate. It was illustrated that scheelite particles were dispersed in ultrapure water at natural $\mathrm{pH} 5.6$ because no attraction force appeared. Classical DLVO theoretical model (the green solid line) could not be well fitted with the curves, as strong repulsive forces were observed at less than a separation distance of $5 \mathrm{~nm}$. The repulsive force had been proved by Israelachvili and Adams [43] between mica surfaces in aqueous $\mathrm{KNO}_{3}$ solution. This non-DLVO force was named hydration force, which acts on hydrophilic particles when the separation distance is less than about $4 \mathrm{~nm}$ [19]. The interaction force between scheelite and scheelite could be explained by the EDLVO theoretical model (the red solid line). Although the red line could not perfectly match the approach curves, the trend was clear. A slight jump-in was observed between scheelite and scheelite in ultrapure water of $\mathrm{pH} 8$ or $\mathrm{pH} 10$ when approaching. These results indicated that van der Waals forces overcame electrical double layer repulsion force to attract scheelite particles to the surface at $\mathrm{pH} 8$ or $\mathrm{pH} 10$, and scheelite particles could be attracted to each other in ultrapure water, which had been proved by the photo of optical microscope in Figure 8(b). An adhesion force of $1 \mathrm{nN}$ at $15 \mathrm{~nm}$ separation distance was obtained between scheelite and scheelite at natural pH 5.6 as shown in Figure 13(b). With the increase of $\mathrm{pH}$, the adhesion force greatly enhanced, which was $5 \mathrm{nN}$ at $40 \mathrm{~nm}$ separation distance at $\mathrm{pH} 10$ and $8 \mathrm{nN}$ at $100 \mathrm{~nm}$ separation distance at $\mathrm{pH} 8$. This may be because scheelite surface was negatively charged at the range of $\mathrm{pH}$ from 5.6 to 10 and the addition of $\mathrm{Na}$ ions reduced the electric double layer repulsive force [27], so scheelite particles were easy to attract together at $\mathrm{pH} 10$.

As demonstrated in Figure 14(a), a jump-in was not observed between scheelite and fluorite when measured in natural ultrapure water $(\mathrm{pH}$ 5.6) in the approach curves. According to the results in the curves, scheelite and fluorite particles in ultrapure water $(\mathrm{pH} 5.6)$ could not attract each other obviously due to repulsive force. With the increase of $\mathrm{pH}$, a light jump-in was observed at the separation distance of $30 \mathrm{~nm}$ at $\mathrm{pH} 8$ and 10. Here, van der Waals force contributed the main force by overcoming the electrical double layer force, indicating that scheelite and calcite could agglomerate, but the attraction force (less than $1 \mathrm{nN}$ ) may lead to fracture easily of the agglomeration. As shown in
Figure 14(b), the adhesion force reached the lowest at natural $\mathrm{pH}$ 5.6, and the separation distance of jump-out was $25 \mathrm{~nm}$. The adhesion force increased with the increase of $\mathrm{pH}$ and reached $6 \mathrm{nN}$ of separation distance $50 \mathrm{~nm}$ at $\mathrm{pH} 8$. It should be pointed out that the adhesion force reduced obviously on scheelite-fluorite compared with that on scheelite-scheelite under the same condition. The retraction curve results indicated that the separation of fluorite from scheelite would be easier than scheelite from scheelite in flotation. This was because isoelectric point (IEP) of fluorite was $\mathrm{pH} 8.5$ as shown in Figure 6. When the solution $\mathrm{pH}$ was greater than 8.5, the surface of fluorite was negatively charged [44]. When the solution $\mathrm{pH}$ was less than 8.5 , the fluorite surface charged positively, while the scheelite surface charged negatively when the solution $\mathrm{pH}$ was from $\mathrm{pH} 8$ to $\mathrm{pH}$ 10. Therefore, the electrical double-layer force between scheelite and fluorite was an attraction interaction at $\mathrm{pH} 8$ and repulsive interaction at $\mathrm{pH} 10$. So, the adhesion force reduced in the ultrapure water of $\mathrm{pH} 8$, which was consistent with the retraction curves. The force curve results in Figure 14 indicated that the agglomeration could occur between scheelite and fluorite particles in the ultrapure water of $\mathrm{pH} 8$ or 10 , but it was easier to be separated because of tiny adhesion force.

The interaction force curves between scheelite and calcite are shown in Figure 15(a). In the ultrapure water of $\mathrm{pH} 5.6$ or 8 , an obvious jump-in was found at $20 \mathrm{~nm}$ separation distance. This was because the surface of calcite was positively charged at $\mathrm{pH} 5.6$ or 8 , while the surface of scheelite was negatively charged with $\mathrm{pH}$ range of 5.6 to 8 , so the electrical double layer force between scheelite and calcite exhibited an attraction force, and van der Waals force also exhibited an attraction force. The interaction force curves could be well described by the DLVO theory when the separation distance was away from $10 \mathrm{~nm}$ at $\mathrm{pH}$ 10. Under this condition, the zeta potential of calcite was close to $0 \mathrm{mv}$, which led to the minimum electrical double layer force between scheelite and calcite, and the interaction force on scheelite-calcite was also minimum, so an adhesion force of $3 \mathrm{nN}$ at $18 \mathrm{~nm}$ separation distance at $\mathrm{pH}$ 10 is shown in Figure 10(b).

In a word, scheelite-scheelite and scheelite-fluorite particles were all dispersed in natural ultrapure water $(\mathrm{pH}$ 5.6), while scheelite-calcite particles could attract each other. With the increase of $\mathrm{pH}$, scheelite-scheelite, scheelite-fluorite, and scheelite-calcite particles could attract each other to form agglomerates at $\mathrm{pH} 10$, which would affect the flotation of fine scheelite.

3.4.2. Interaction Forces on Scheelite-Scheelite, ScheeliteFluorite, and Scheelite-Calcite in Sodium Oleate Solution. As shown in Figure 16, a strong jump-in was observed on scheelite-scheelite, scheelite-fluorite, and scheelite-calcite from interaction force curves after the scheelite, fluorite, and calcite substrates had been soaked in $0.1 \mathrm{mM} / 1 \mathrm{mM}$ sodium oleate solution of $\mathrm{pH} 8$ or 10 for 30 minutes. It should be noted that there is no force curve data of scheelite-scheelite in $1 \mathrm{mM}$ sodium oleate solution ( $\mathrm{pH}$ 


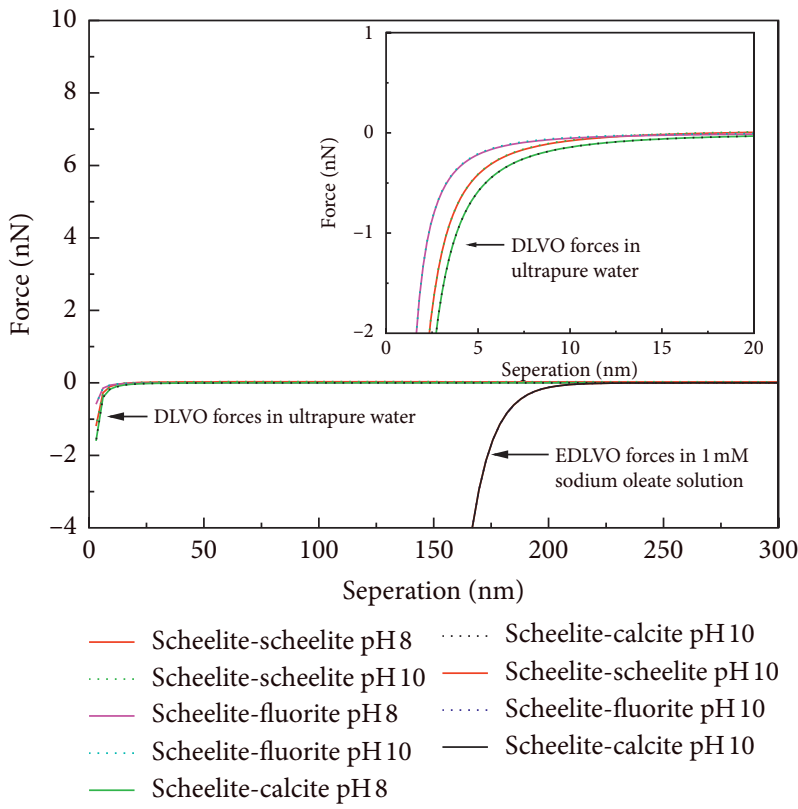

FIGURE 12: DLVO and EDLVO forces on scheelite-scheelite, scheelite-fluorite, and scheelite-calcite (in pure water of pH 8 or 10, $\gamma^{-1}=960 \mathrm{~nm}$ [18], and $R=5 * 10^{-9} \mathrm{~m}$; in $1 \mathrm{mM}$ sodium oleate solution of $\mathrm{pH} 10, \gamma^{-1}=9.6 \mathrm{~nm}[18]$, and $K_{\text {hydrophobic }}=-1.4 * 10^{8} \mathrm{nN} / \mathrm{m}[15]$ ).

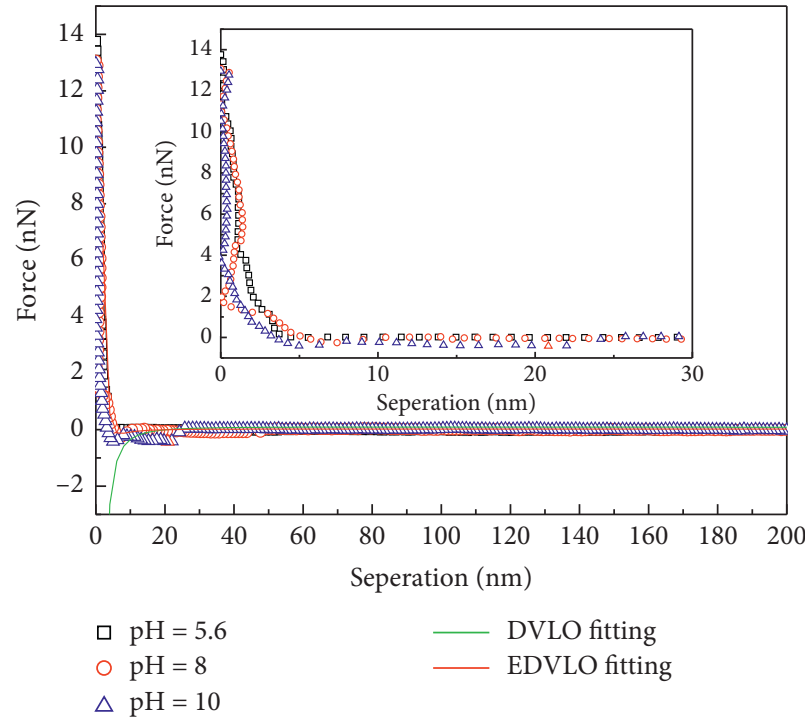

(a)

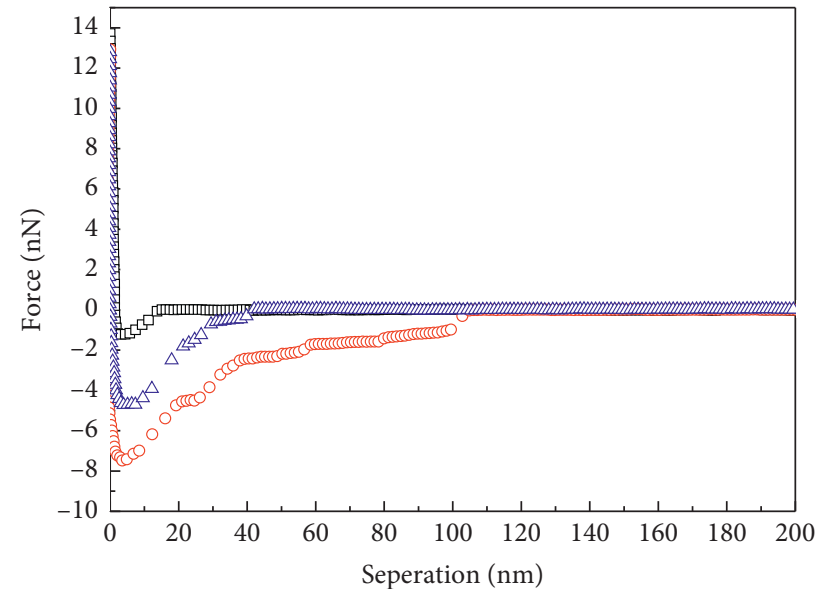
$\square \mathrm{pH}=5.6$
$\circ \mathrm{pH}=8$
$\triangle \mathrm{pH}=10$

FIGURE 13: The interaction forces between scheelite particle and scheelite substrate in ultrapure water solution: (a) approach curves; (b) retraction curves.

10); this may be because the force exceeds the elastic constant of the colloidal probe, so the force curve is not obtained using AFM. These results indicated that the hydrophobic forces exhibited attractive between particles and surfaces. Previous studies manifested that the hydrophobic attraction force was several orders of magnitude larger than van der Waals force and electrical double layer force, so the hydrophobic force contributed to the main interaction. It could be found from Figure 16(a) that the hydrophobic force increased with the increase of $\mathrm{pH}$. At
$\mathrm{pH} 10$, the interaction force between scheelite and scheelite was greater than that at $\mathrm{pH} 8$, which indicated that the adsorption effect of sodium oleate on scheelite surface was better at $\mathrm{pH} 10$. This result was consistent with the previous research [45]. When the concentration of sodium oleate is $0.1 \mathrm{mM}$, according to species distribution diagram [46] of the oleic acid solution, the maximum $\mathrm{pH}$ of ionmolecular association concentration is 8.21. Accordingly, the sodium oleate mainly existed in the form of $\mathrm{RCOO}^{-}$ and $\mathrm{RCOO}_{2}{ }^{2-}$ at $\mathrm{pH} 10$, and the surface of scheelite 


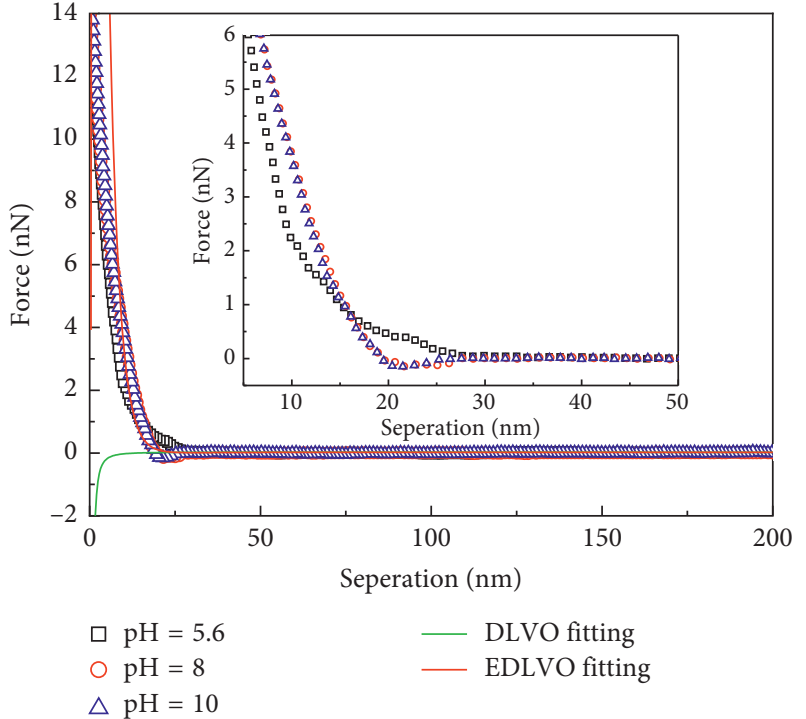

(a)

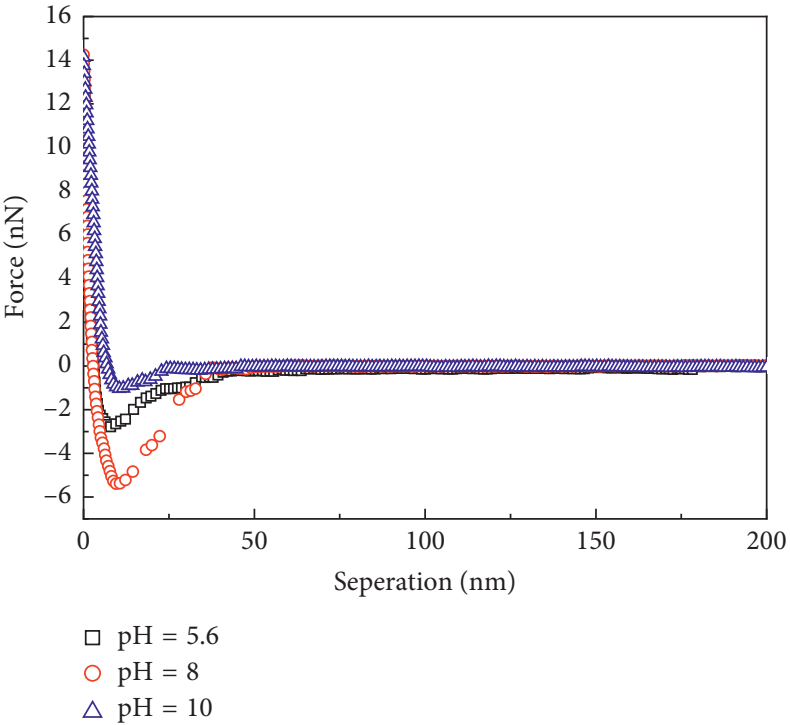

(b)

FIGURE 14: The interaction forces between scheelite particle and fluorite substrate in ultrapure water solution: (a) approach curves; (b) retraction curves.

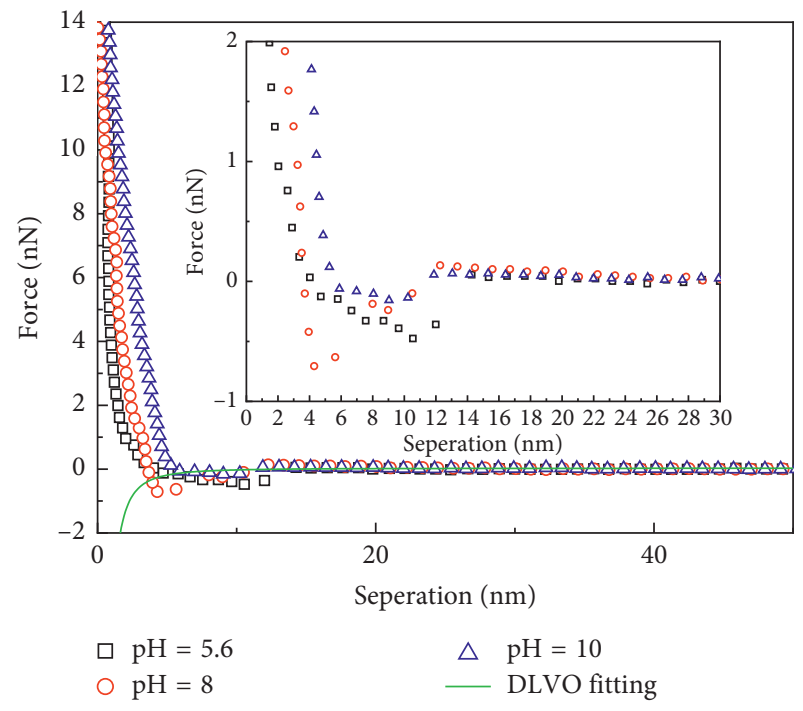

(a)

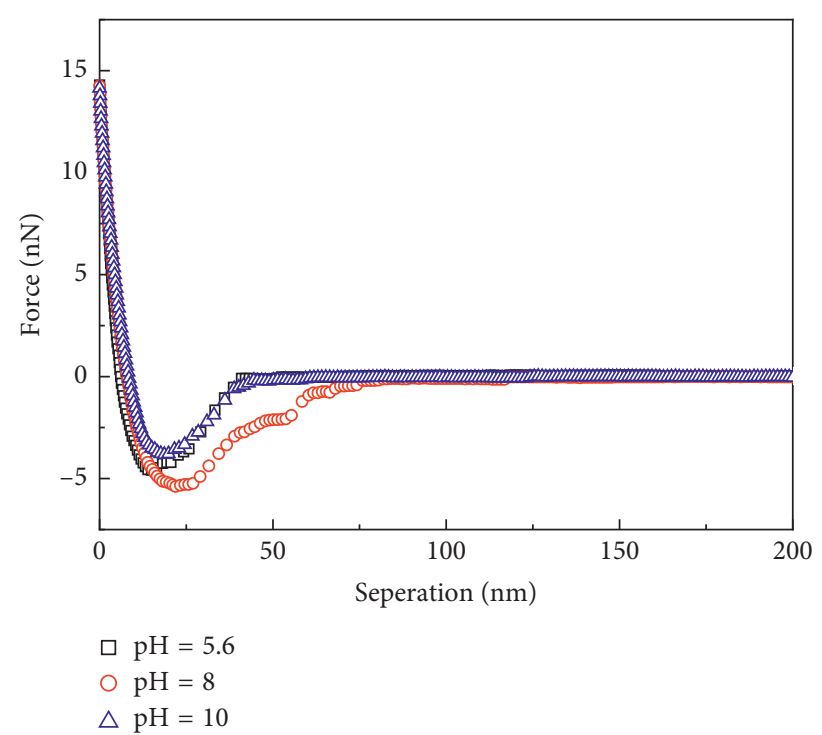

(b)

FIGURE 15: The interaction forces between scheelite particle and calcite substrate in ultrapure water solution: (a) approach curves; (b) retraction curves.

charged negatively under the same condition is shown in Figure 6 . Therefore, the sodium oleate was adsorbed on the surface of scheelite by chemisorption. However, at $\mathrm{pH} 8$, the sodium oleate mainly existed in the form of oleic acid molecule $\mathrm{RCOOH}$ [47]; consequently, the sodium oleate was adsorbed on the surface of scheelite by physical absorption. The approach curves could be well described by EDLVO theoretical model (red and blank solid line) in Figure 16(a). However, the EDLVO fitting line did not appear in Figures 16(b) and 16(c) due to irregularity of the approach curves. It may be caused by mineral surface heterogeneity and limitation of elastic coefficient on the scheelite colloid probe. The same phenomenon was also found on scheelite-fluorite and scheelite-calcite after treating with $0.1 \mathrm{mM} / 1 \mathrm{mM}$ sodium oleate solution as shown in Figures 16(b) and 16(c). The hydrophobic force increased obviously in $1 \mathrm{mM}$ sodium oleate solution compared to that in $0.1 \mathrm{mM}$ sodium oleate solution. An attractive force of $8 \mathrm{nN}$ at $28 \mathrm{~nm}$ separation distance was obtained between scheelite and fluorite after treating with $1 \mathrm{mM}$ sodium oleate as shown 


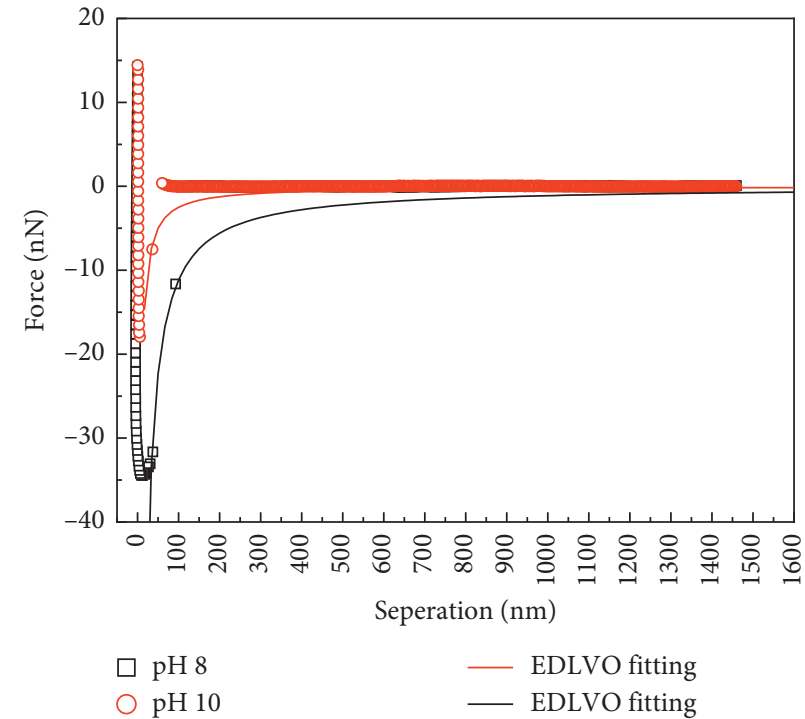

(a)

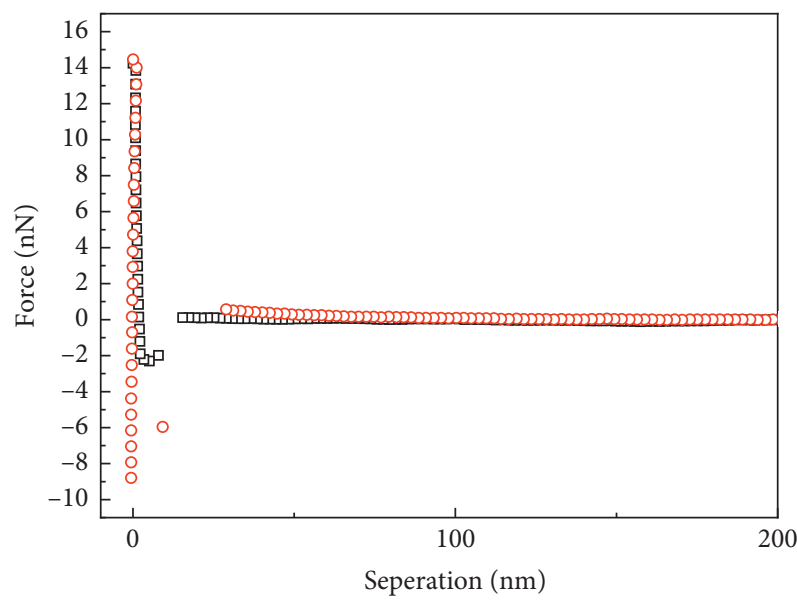

$\square$ Treated with $0.1 \mathrm{mM}$ sodium oleate solution

Treated with $1 \mathrm{mM}$ sodium oleate solution

(b)

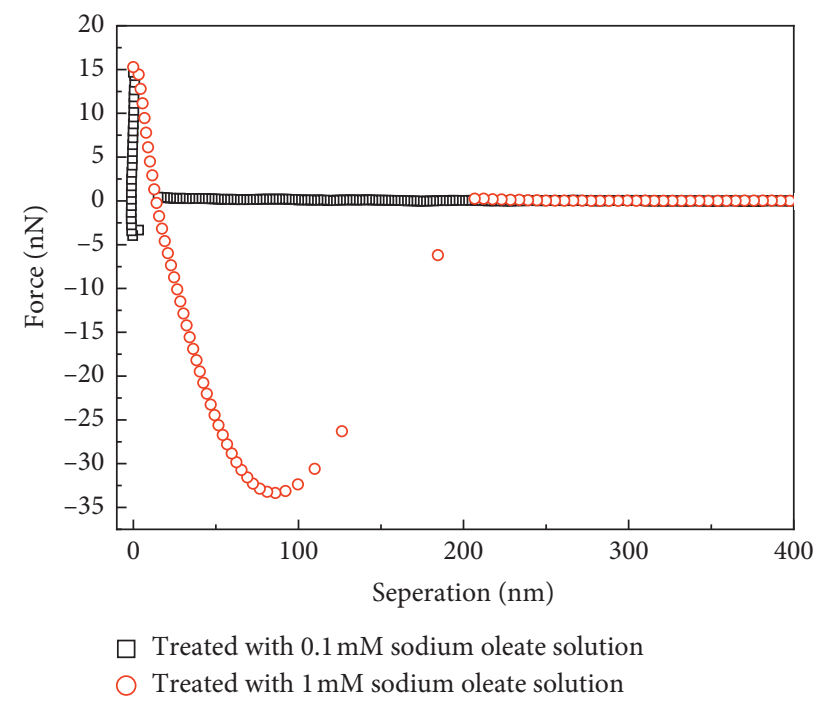

(c)

FIGURE 16: The approach curves in sodium oleate solution: (a) scheelite-scheelite in $0.1 \mathrm{mM}$ sodium oleate solution; (b) scheelite-fluorite; (c) scheelite-calcite.

in Figure 16(b), and an attraction force of $33 \mathrm{nN}$ at $195 \mathrm{~nm}$ separation distance was obtained between scheelite and calcite in the same experiment condition as shown in Figure 16(c). All the results above indicated that the main formation reason of hydrophobic agglomeration was the existence of hydrophobic force after the minerals were treated with the sodium oleate solution .

As shown in Figures 17 and 18, the jump-in distance and force on scheelite-scheelite, scheelite-fluorite, and scheelitecalcite in approach curves at $\mathrm{pH} 10$ were compared. The jump-in distance and force were almost similar in ultrapure water, but increased obviously in $0.1 \mathrm{mM}$ and $1 \mathrm{mM}$ sodium oleate solution, which fully showed that agglomerations were easier to form in higher concentration of sodium oleate. After treated with $0.1 \mathrm{mM}$ sodium oleate, the jump-in distance and force were ordered as follows: scheelite- scheelite $>$ scheelite-calcite $>$ scheelite-fluorite, which was consistent with the result of adhesion force in Figure 19. These results indicated that the agglomerations on scheelitescheelite were easiest to be formed, and hardest to fracture.

Previous studies [21] reported a simplified model (equation (11)) for calculating the adhesion between a particle and a surface with nanoscale roughness. The increase of adhesion force may be related to $R_{q}$.

$$
\frac{F_{\mathrm{ad}}}{R}=\frac{A_{12}}{6 Z_{0}^{2}\left[\left(1.485 R_{q} / 1.485 R_{q}+R\right)+\left(1 /\left(1+1.485 R_{q}\right) / Z_{0}\right)^{2}\right]},
$$

where $Z_{0}$ is the equilibrium distance (closest approach) between two surfaces, which is usually taken as $0.3 \mathrm{~nm}$ [48], $A_{12}$ is the Hamaker constant for mineral 1 interacting with 


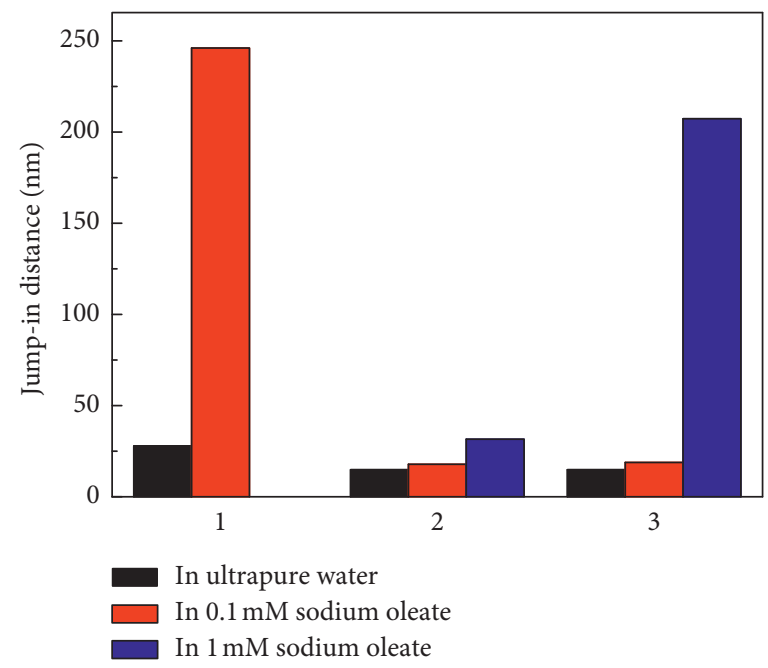

FIGURE 17: The jump-in distance on scheelite-scheelite, scheelite-fluorite, and scheelite-calcite in approach curves at pH 10.

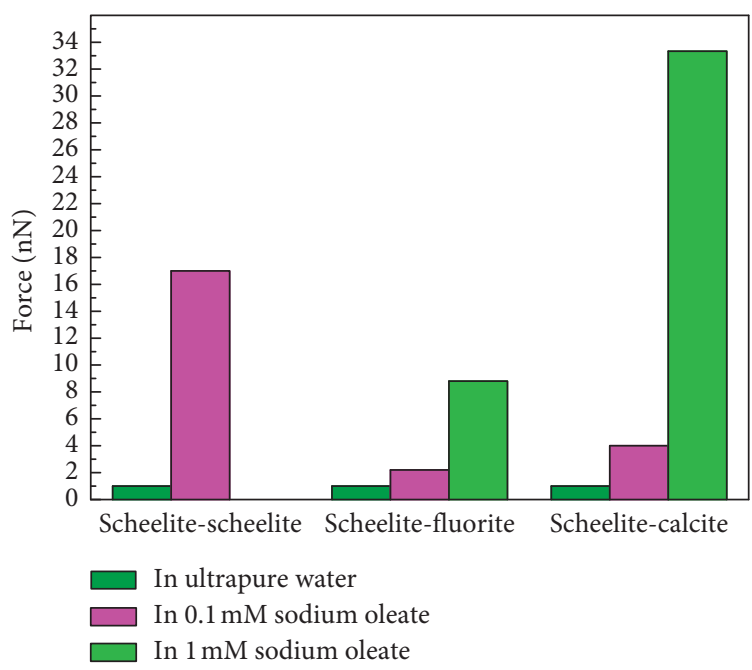

FIGURE 18: The force on scheelite-scheelite, scheelite-fluorite, and scheelite-calcite in approach curves at pH 10.

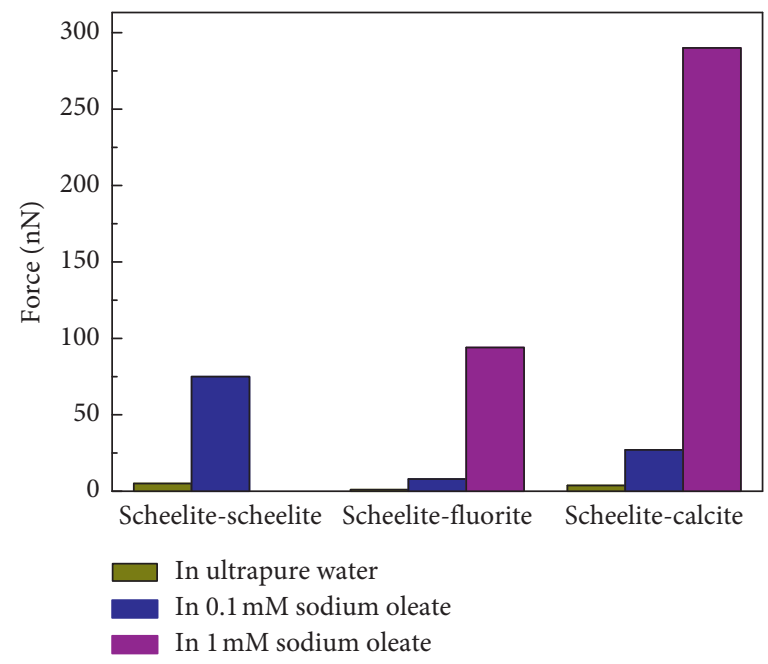

FIGURE 19: The adhesion force on scheelite-scheelite, scheelite-fluorite, and scheelite-calcite in retraction curves at pH 10. 


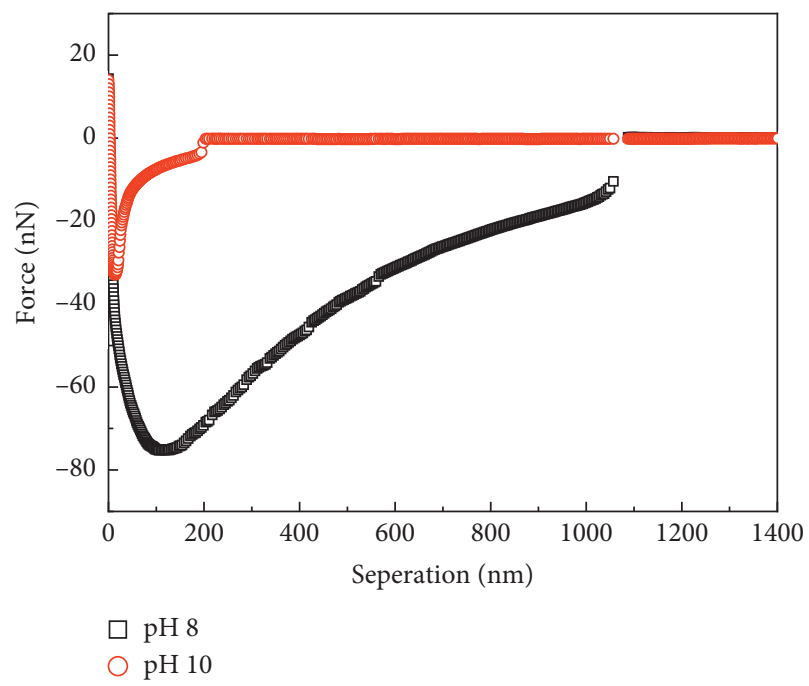

(a)

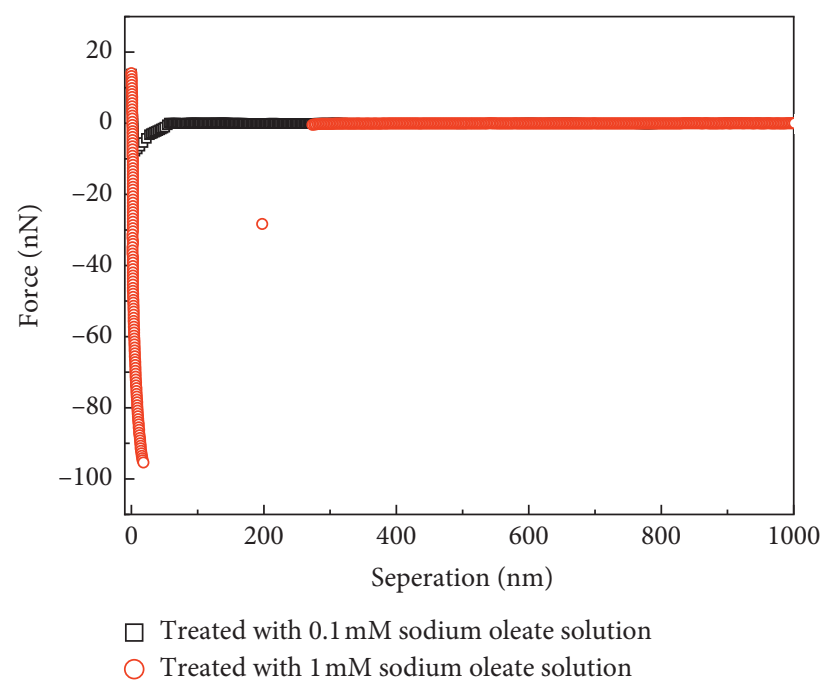

(b)

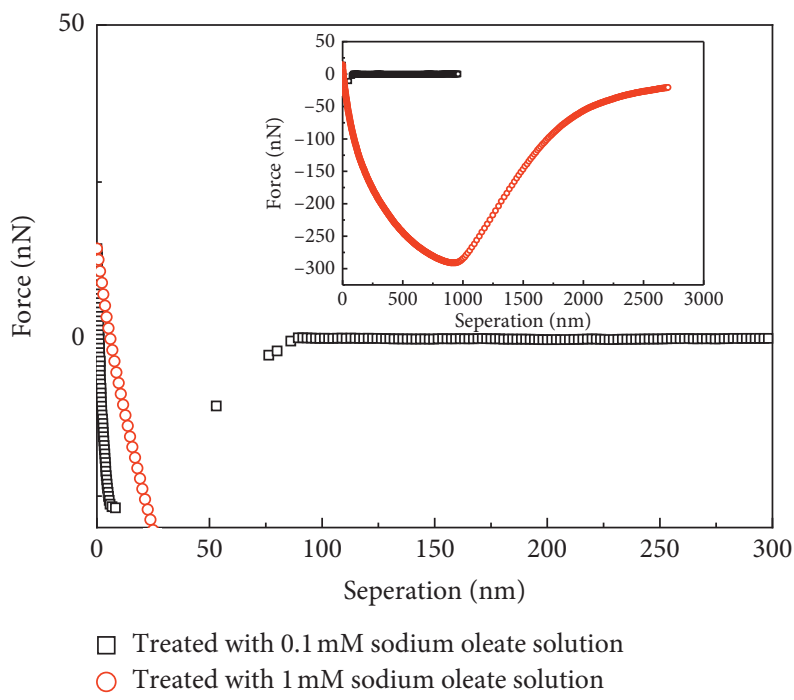

(c)

FIGURE 20: The retraction curves in sodium oleate solution: (a) scheelite-scheelite in $0.1 \mathrm{mM}$ sodium oleate solution; (b) scheelite-fluorite; (c) scheelite-calcite.

mineral 2 in vacuum or air, and $R_{q}$ is the roughness of mineral surface.

As shown in Figures 19 and 20, the adhesion forces of scheelite-scheelite, scheelite-fluorite, and scheelite-calcite increased obviously after treating with $0.1 \mathrm{mM} / 1 \mathrm{mM}$ sodium oleate solution and increased with the increase of sodium oleate concentration and so did the corresponding separation distance. The adhesion force of scheelite-scheelite was strongest after treated with $0.1 \mathrm{mM}$ sodium oleate solution ( $\mathrm{pH} 10)$ compared with adhesion forces in Figures20(b) and 20(c). This may be because the roughness when sodium oleate was adsorbed on scheelite particle had been changed due to equation (11).

All the above results indicated hydrophobic force played a key role in the formation of agglomerates. The agglomerates were attracted by hydrophobic force pushing hydration layer out. The interaction forces changed to strong adhesion forces, and the long separation distance also verified these results. The agglomeration formed between scheelite and scheelite made the fine scheelite particles grow, which was conducive to improving the efficiency of scheelite flotation. The agglomeration formed between scheelite and fluorite and scheelite and calcite seriously affected the grade and recovery of scheelite concentrate. Therefore, effective inhibitors of fluorite and calcite must be used to prevent the formation of agglomerations in the flotation process of fine scheelite.

\section{Conclusions}

Hydrophobic aggregation flotation is a typical process in fine scheelite flotation. The interaction forces on scheelitescheelite, scheelite-fluorite, and scheelite-calcite in ultrapure 
water and sodium oleate solution were examined by using the AFM colloid probe technique. The corresponding optical microscope measurements, zeta potential measurements, and contact angle measurements were also carried out to verify the AFM results in this paper.

(1) The surface of natural scheelite, fluorite, and calcite was hydrophilic according to contact angle measurements results.A strong hydration force existedin the interaction force curves on hydrophilic scheelite-scheelite and scheelite-fluorite in ultrapure water ( $\mathrm{pH}$ 5.6). The results implied that on scheelite-scheelite, scheelitefluorite particles were dispersed in scheelite flotation. However, scheelite-calcite may be easy to attract each other at $\mathrm{pH} 5.6$ because of the weak attractive force. With the increase of $\mathrm{pH}$, a slight jump-in was found in the interaction force curves on scheelite-scheelite, scheelite-fluorite, and scheelite-calcite at $\mathrm{pH} 8$ or 10. The formation of agglomerates on scheelite-scheelite, scheelite-fluorite, and scheelite-calcite was proved by optical microscope measurements results, but the agglomerations were empty and not tight.

(2) The adsorption of the sodium oleate on the surface of scheelite, fluorite, and calcite was proved by zeta potential measurements results. Furthermore, the surface of scheelite, fluorite, and calcite treated by sodium oleate solution was hydrophobic according to contact angle measurements results. The interaction force increased obviously because of the existing hydrophobic force, which could be well described by EDLVO theory, which was verified by the corresponding optical microscope measurements. Hydrophobic agglomerations could form on scheelite-scheelite, scheelite-fluorite, and scheelitecalcite treated by sodium oleate solution, which were proved by optical microscope measurements results. Furthermore, optical microscope measurements results indicated the hydrophobic agglomerations were larger and more dense when the particles of scheelite, fluorite, and calcite were soaked by sodium oleate, which was proved by the adhesion force curves.

(3) All results show that fluorite and calcite must be effectively restrained to prevent them from agglomerating with scheelite in the flotation process, which can reduce the grade and recovery of scheelite concentrate. The interaction on scheelite-scheelite, scheelite-fluorite, and scheelite-calcite still needs to be further studied after treated by inhibitor using AFM.

\section{Data Availability}

All data included in this study are available upon request by contacting the corresponding author.

\section{Conflicts of Interest}

The authors declare no conflicts of interest.

\section{Acknowledgments}

The authors thank China Nanjing Hongchuang Exploration Technology Service Co., Ltd., for preparing the surface of scheelite, fluorite, and calcite minerals used in AFM and also thank the Chinese National Engineering Research Center of Coal Preparation and Purification for providing the atomic force microscope testing service. The authors also thank $\mathrm{PhD}$ candidate Hai Liu for helping with language editing. This work was financially supported by China Tungsten \& Hightech Material Co., Ltd.

\section{References}

[1] N. Kupka and M. Rudolph, "Froth flotation of scheelite-a review," International Journal of Mining Science and Technology, vol. 28, no. 3, pp. 373-384, 2018.

[2] T. V. Subrahmanyam and K. S. E. Forssberg, "Fine particles processing: shear-flocculation and carrier flotation-a review," International Journal of Mineral Processing, vol. 30, no. 3-4, pp. 265-286, 1990.

[3] A. Ozkan, "Determination of the critical surface tension of wetting of minerals treated with surfactants by shear flocculation approach," Journal of Colloid and Interface Science, vol. 277, no. 2, pp. 437-442, 2004.

[4] W. Zhou, H. Chen, L. Ou, and Q. Shi, "Aggregation of ultrafine scheelite particles induced by hydrodynamic cavitation," International Journal of Mineral Processing, vol. 157, pp. 236-240, 2016.

[5] L. J. Warren, "Shear-flocculation of ultrafine scheelite in sodium oleate solutions," Journal of Colloid and Interface Science, vol. 50, no. 2, pp. 307-318, 1975.

[6] L. Valderrama and J. Rubio, "High intensity conditioning and the carrier flotation of gold fine particles," International Journal of Mineral Processing, vol. 52, no. 4, pp. 273-285, 1998.

[7] S. Song, A. Lopez-Valdivieso, J. L. Reyes-Bahena, H. I. Bermejo-Perez, and O. Trass, "Hydrophobic flocculation of galena fines in aqueous suspensions," Journal of Colloid and Interface Science, vol. 227, no. 2, pp. 272-281, 2000.

[8] C. Zhang, L. Li, Z. Yuan, X. Xu, Z. Song, and Y. R. Zhang, "Mechanical properties of siderite and hematite from DFT calculation," Minerals Engineering, vol. 146, Article ID 106107, 2020.

[9] R. Wang, Z. Wei, H. Han et al., "Fluorite particles as a novel calcite recovery depressant in scheelite flotation using $\mathrm{Pb}$ BHA complexes as collectors," Minerals Engineering, vol. 132, pp. 84-91, 2019.

[10] H. Han, Y. Xiao, Y. Hu et al., "Replacing Petrov's process with atmospheric flotation using $\mathrm{Pb}-\mathrm{BHA}$ complexes for separating scheelite from fluorite," Minerals Engineering, vol. 145, Article ID 106053, 2020.

[11] W. Chen, F. Chen, X. Bu, G. Zhang, C. Zhang, and Y. Song, "A significant improvement of fine scheelite flotation through rheological control of flotation pulp by using garnet," Minerals Engineering, vol. 138, pp. 257-266, 2019.

[12] L. J. Warren, "Flocculation of stirred suspensions of cassiterite and tourmaline," Colloids and Surfaces, vol. 5, no. 4, pp. 301-319, 1982.

[13] P. Koh and L. Warren, "A pilot plant test of the shear-flocculation of ultrafine scheelite," in Proceedings of the Chemeca 80: Process Industries in the 80's; 8th Australian Chemical 
Engineering Conference, p. 90, Melbourne, Australia, August 1980.

[14] Y. Xing, M. Xu, X. Gui et al., "The application of atomic force microscopy in mineral flotation," Advances in Colloid and Interface Science, vol. 256, pp. 373-392, 2018.

[15] J. Israelachvili and R. Pashley, "The hydrophobic interaction is long range, decaying exponentially with distance," Nature, vol. 300, no. 5890, pp. 341-342, 1982.

[16] R. M. Pashley and J. N. Israelachvili, "A comparison of surface forces and interfacial properties of mica in purified surfactant solutions," Colloids and Surfaces, vol. 2, no. 2, pp. 169-187, 1981.

[17] A. Nguyen and H. J. Schulze, Colloidal Science of Flotation, CRC Press, Boca Raton, FL, USA, 2003.

[18] J. N. Israelachvili, Intermolecular and Surface Forces, Academic Press, Cambridge, MA, USA, 2015.

[19] H.-J. Butt, B. Cappella, and M. Kappl, "Force measurements with the atomic force microscope: technique, interpretation and applications," Surface Science Reports, vol. 59, no. 1-6, pp. 1-152, 2005.

[20] B. Cappella and G. Dietler, "Force-distance curves by atomic force microscopy," Surface Science Reports, vol. 34, no. 1-3, pp. 1-104, 1999.

[21] J. Wang, J. Li, L. Xie, C. Shi, Q. Liu, and H. Zeng, "Interactions between elemental selenium and hydrophilic/hydrophobic surfaces: direct force measurements using AFM," Chemical Engineering Journal, vol. 303, pp. 646-654, 2016.

[22] J. Drelich, J. Nalaskowski, A. Gosiewska, E. Beach, and J. D. Miller, "Long-range attractive forces and energy barriers in de-inking flotation: AFM studies of interactions between polyethylene and toner," Journal of Adhesion Science and Technology, vol. 14, no. 14, pp. 1829-1843, 2000.

[23] Y. Xing, C. Li, and Y. Cao, "Interaction forces between paraffin/stearic acid and fresh/oxidized coal particles measured by atomic force microscopy," Energy \& Fuels, vol. 31, no. 3, pp. 3305-3312, 2017.

[24] E. Rohem Peçanha, M. D. da Fonseca de Albuquerque, R. A. Simão, L. de Salles Leal Filho, and M. B. de Mello Monte, "Interaction forces between colloidal starch and quartz and hematite particles in mineral flotation," Colloids and Surfaces A: Physicochemical and Engineering Aspects, vol. 562, pp. 79-85, 2019.

[25] X. Gui, Y. Xing, G. Rong, Y. Cao, and J. Liu, "Interaction forces between coal and kaolinite particles measured by atomic force microscopy," Powder Technology, vol. 301, pp. 349-355, 2016.

[26] W. A. Ducker, T. J. Senden, and R. M. Pashley, "Direct measurement of colloidal forces using an atomic force microscope," Nature, vol. 353, no. 6341, pp. 239-241, 1991.

[27] H.-J. Butt, "Measuring electrostatic, Van der Waals, and hydration forces in electrolyte solutions with an atomic force microscope," Biophysical Journal, vol. 60, no. 6, pp. 14381444, 1991.

[28] Z. Zhang, Y. Cao, L. Sun, Z. Ma, and Y. Liao, "Interaction forces between scheelite and fluorite in calcium solution measured by atomic force microscopy," Applied Surface Science, vol. 486, pp. 323-336, 2019.

[29] L. Xie, J. Wang, C. Shi et al., "Mapping the nanoscale heterogeneity of surface hydrophobicity on the sphalerite mineral," The Journal of Physical Chemistry C, vol. 121, no. 10, pp. 5620-5628, 2017.

[30] Z. Lu, Q. Liu, Z. Xu, and H. Zeng, "Probing anisotropic surface properties of molybdenite by direct force measurements," Langmuir, vol. 31, no. 42, pp. 11409-11418, 2015.
[31] A. Beaussart, L. Parkinson, A. Mierczynska-Vasilev, and D. A. Beattie, "Adsorption of modified dextrins on molybdenite: AFM imaging, contact angle, and flotation studies," Journal of Colloid and Interface Science, vol. 368, no. 1, pp. 608-615, 2012.

[32] Z. Gao, Y. Hu, W. Sun, and J. W. Drelich, "Surface-charge anisotropy of scheelite crystals," Langmuir, vol. 32, no. 25, pp. 6282-6288, 2016.

[33] S. Assemi, J. Nalaskowski, J. D. Miller, and W. P. Johnson, "Isoelectric point of fluorite by direct force measurements using atomic force microscopy," Langmuir, vol. 22, no. 4, pp. 1403-1405, 2006.

[34] W. Chen, Q. Feng, G. Zhang, L. Li, and S. Jin, "Effect of energy input on flocculation process and flotation performance of fine scheelite using sodium oleate," Minerals Engineering, vol. 112, pp. 27-35, 2017.

[35] J. Wang, Y. Mao, Y. Cheng, Y. Xiao, Y. Zhang, and J. Bai, "Effect of $\mathrm{Pb}$ (II) on the flotation behavior of scheelite using sodium oleate as collector," Minerals Engineering, vol. 136, pp. 161-167, 2019.

[36] B. A. Wills, Chapter 12-Froth Flotation, B. A. Wills, Ed., O'Reilly Media, Inc., Newton, MA, USA, 1985.

[37] B. Derjaguin and L. Landau, "Theory of the stability of strongly charged lyophobic sols and of the adhesion of strongly charged particles in solutions of electrolytes," Progress in Surface Science, vol. 43, no. 1-4, pp. 30-59, 1993.

[38] E. J. W. Verwey, "Theory of the stability of lyophobic colloids," The Journal of Physical and Colloid Chemistry, vol. 51, no. 3, pp. 631-636, 1947.

[39] X.-T. Huang, W. Xiao, H.-B. Zhao et al., "Hydrophobic flocculation flotation of rutile fines in presence of styryl phosphonic acid," Transactions of Nonferrous Metals Society of China, vol. 28, no. 7, pp. 1424-1432, 2018.

[40] G. Qiu, Y. Hu, and D. Wang, Particle Interaction and Fine Particle Flotation, Central South University Press, Changsha, China, 1993.

[41] X. Liu, Study on Flotation Behavior of Fine-Grained Scheelite Study on Flotation Behavior of Fine-Grained Scheelite, Central South University, Changsha, China, 2010.

[42] J. Visser, "On Hamaker constants: a comparison between Hamaker constants and Lifshitz-Van der Waals constants," Advances in Colloid and Interface Science, vol. 3, no. 4, pp. 331-363, 1972.

[43] J. N. Israelachvili and G. E. Adams, "Direct measurement of long range forces between two mica surfaces in aqueous $\mathrm{KNO}_{3}$ solutions," Nature, vol. 262, no. 5571, pp. 774-776, 1976.

[44] J. D. Miller, K. Fa, J. V. Calara, and V. K. Paruchuri, "The surface charge of fluorite in the absence of surface carbonation," Colloids and Surfaces A: Physicochemical and Engineering Aspects, vol. 238, no. 1-3, pp. 91-97, 2004.

[45] W.-Z. Yin and J.-Z. Wang, "Effects of particle size and particle interactions on scheelite flotation," Transactions of Nonferrous Metals Society of China, vol. 24, no. 11, pp. 3682-3687, 2014.

[46] P. Somasundaran and D. Wang, Solution Chemistry: Minerals and Reagents, Elsevier, Amsterdam, Netherlands, 2006.

[47] P. Somasundaran, K. P. Ananthapadmanabhan, and I. B. Ivanov, "Dimerization of oleate in aqueous solutions," Journal of Colloid and Interface Science, vol. 99, no. 1, pp. 128-135, 1984.

[48] Y. I. Rabinovich, J. J. Adler, A. Ata, R. K. Singh, and B. M. Moudgil, "Adhesion between nanoscale rough surfaces," Journal of Colloid and Interface Science, vol. 232, no. 1, pp. 17-24, 2000. 